ICAMS $2016-6^{\text {th }}$ International Conference on Advanced Materials and Systems

\title{
EFFECT OF VARIOUS TANNING PROCESSES ON CHARACTERISTICS OF LINING LEATHERS
}

\author{
GÖKHAN ZENGIN, SINA POURRASOUL SARDROUDI, BEHZAT ORAL BITLISLI, ARIFE \\ CANDAȘ ADIGÜZEL ZENGIN* \\ Ege University, Engineering Faculty, Leather Engineering Department, Bornova, zmir, 35100, \\ Turkey,+902323114401, *corresponding author: adiguzel.candas@gmail.com
}

\begin{abstract}
Wear comfort, fit, and durability and more significantly linings are the main factors that affect the quality of shoe upper leathers. Lining leathers are generally produced from goat skins, cowhides as well as sheepskins mostly depending on the customer demands. Over the last few decades, soft, breathable and comfortable linings that provide a healthy environment for the feet skin have gained importance. As it is well known that tanning procedure has a direct influence on the above mentioned properties of the manufactured lining goods, this study aimed to determine the effect of different tanning processes on the wear comfort and lining characteristics of leathers for the foot health and wear comfort. For this purpose, the effect of four different tanning techniques was investigated on properties of lining leathers produced from goat skins in terms of dynamic and static water absorption, color fastness to perspiration, to and fro and crockmeter rubbing fastness tests. The tanning process of pickled goat skins was differentiated by applying wet-white, vegetable, mineral, and semi tanning procedures. Post tanning processes were carried out in accordance with the same conventional formulation throughout the production of the lining leathers. The findings reveal that different tanning techniques had a significant impact on the lining characteristics and the tanning method could be selected according to the use of the linings in variable shoe types and the customer demands.
\end{abstract}

Keywords: lining leathers, tanning, perspiration, water absorption

\section{INTRODUCTION}

Footwear is an important wear material used by human life. Various types of footwear produced by various types of materials have been developed. The footwear produced for industrial, agricultural, military, athletic and artistic purposes have certain differences and directly affect the wear comfort of the foot wears. Therefore, appropriate materials and manufacturing techniques should be taken into consideration for the footwear manufacturing (Bitlisli et al., 2005; Śmiechowski et al., 2014).

Lining leathers are one of the main factors that affect the quality of shoe upper leathers in addition to wear comfort and durability. The comfort of lining leather could be explained in terms of a comfort provided by the leather characteristics including various physical properties such as water absorption, rubbing and perspiration properties as well as water vapor permeability (Sari and Basaran, 1996; Sari and Bitlisli, 1996; Bitlisli et al., 2005). Nowadays soft, breathable and comfortable linings that provide a healthy environment for the feet skin have gained importance due to the customer demands. Although limited number of literatures describing the lining leather properties was found, they were published in earlier times (Diebschlag et al., 1976; Hernon, 1981; Shuttleworth, 1973) and no report was found addressing the effect of tanning technique on the lining leather properties and their effect on wear comfort in the current literatures.

In this study, the effect of four different tanning techniques such as wet-white, vegetable, mineral, and semi tannings was investigated on physical and comfort properties of lining leathers produced from goat skins in terms of dynamic and static water absorption, color fastness to perspiration, to and fro and crockmeter rubbing fastness tests. 


\section{MATERIAL AND METHOD}

\section{Material}

In this study, domestic pickled goat leathers were used for the tanning process of the lining leathers. The conventional leather chemicals were used in the leather manufacturing processes.

\section{Method}

\section{The Tanning Procedure}

Chrome, vegetable, wet white and semi (chrome and vegetable tannin combination) tanning techniques were selected for the study. After conventional depickling, bating and degreasing processes, the tanning began with the pickling procedure. Chromium ( $8 \%$ chromium salt), vegetable (16\% vegetable tanning, 5\% synthetic tannin), wet-white (2.5 phosphonium and 3\% aluminum tri formiate), and semi (3\% chromium salt, $13 \%$ vegetable tannin) tanning procedures were performed conventionally. The tanning processes were followed by post tanning operation in terms of neutralization and fatliquoring using the combination of sulphited, phosphate and lubricating synthetic fatliquoring agents. After drying and mechanical operations, the goat skins were converted into crust lining leathers.

Sampling and conditioning of the lining leathers were performed according to TS EN ISO 2418 (2006) and TS EN ISO 2419 (2006) prior to physical tests. Also, the thickness of the leathers was determined with TS 4117 EN ISO 2589 (2006) standard.

\section{Static Water Absorption}

The static water absorption behavior of the lining leathers was tested according to TS 4123 EN ISO 2417. Kubelka apparatus was used for determination of the water absorption of the leathers under static condition and the measurements were carried out at 15 minutes, 30 minutes, $1 \mathrm{~h}, 2 \mathrm{~h}$ and $24 \mathrm{~h}$ of the test.

\section{Dynamic Water Absorption}

The dynamic water absorption property of the lining leathers was examined with the standard of TS 8541 EN ISO 5403. For this study, the aim of this test was to determine the degree of the lining leathers wet-ability.

\section{Color Fastness to Perspiration}

TS EN ISO 11641:2012 standard was used as a method for determining the color fastness to perspiration. This method was for all kinds of leather at all stages of processing.

\section{To and Fro Rubbing Fastness}

The rubbing fastness properties of leathers were examined by Bally Finish Tester 9029 according to TS EN ISO 11640 standard (100 rubs in dry and 25 rubs in wet). Prior and subsequent to the rubbing tests, color measurements were performed and the changes in color were compared. 
ICAMS $2016-6^{\text {th }}$ International Conference on Advanced Materials and Systems

Crock-meter Rubbing Fastness

The crockmeter rubbing fastness of the leathers was performed in accordance with ASTM D5053 standard. The dry and wet rubbing fastness (10 rubs for each) was tested by Atlas CM5 (SDL ATLAS Company, USA) test device. The fabric used in the test was evaluated according to the standard ISO 105-A03 while the leather samples were evaluated as follows; $1=$ Good, $2=$ Medium, $3=$ Poor.

\section{RESULTS AND DISCUSSION}

The thickness values of the lining leathers were determined as $0.83 \pm 0.16 ; 0.83 \pm 0.05$; $0.78 \pm 0.03 ; 0.99 \pm 0.07$ for the chrome, vegetable, semi and wet-white tanning respectively.

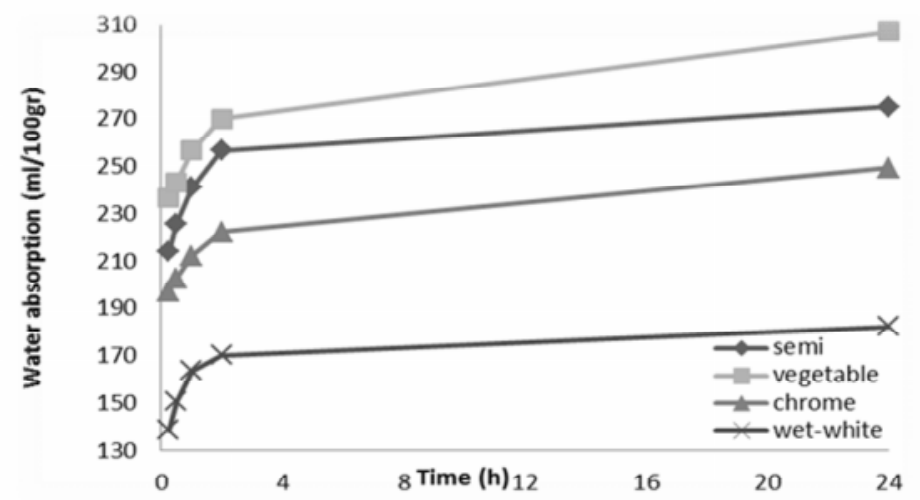

Figure 1. Kubelka (Static water absorption) values of lining leathers (ml/100gr)

Static water absorption (Kubelka) test results are shown in Figure 1. The highest water absorption was determined from the vegetable tanned lining leathers due to their hydrophilic structure. Semi tanned lining leather was in the second place while the wetwhite tanned lining leather had the minimum water absorption value as $182.54 \mathrm{ml}$ water for $100 \mathrm{gr}$ leather.

The recommended water absorption is a minimum of $100 \%$ for linings and insoles for 24 hours (TS EN 344-1, 1998; Bitlisli et al., 2005) that is a well indication of high water absorption quality requirements for linings and insoles. Our static water absorption results were found two fold higher than this requirement such as 274.55 , $307.19,249.57,182.54 \mathrm{~mL} / 100 \mathrm{gr}$ for semi, vegetable, chrome and wet-white tanned lining leathers.

Table 1. Dynamic water absorption (\%) and penetration time of lining leathers

\begin{tabular}{lcc}
\hline Tanning techniques & Water absorption \% & Time (seconds) \\
\hline Chrome & $52.06 \pm 8.8$ & $9 \pm 4.6$ \\
Vegetable & $99.61 \pm 5.9$ & $3 \pm 0.4$ \\
Wet-white & $21.62 \pm 6.0$ & $52 \pm 6.7$ \\
Semi & $102.72 \pm 0.8$ & $3 \pm 0.4$ \\
\hline
\end{tabular}


Dynamic water absorption (\%) results showed that less than minute water was penetrated into the leather in a dynamic condition. Wet-white tanned lining leathers had the longest penetration time (52 seconds) in comparison to other tanning techniques with minimum water absorption (\%) value. Vegetable and semi tanned lining leathers had similar and the highest dynamic water absorption values due to their hydrophilic structure (Table 1). The high water penetration ability of the lining leathers lead to minimum complaints by users who had a feeling uncomfortable feeling in their shoes (Bitlisli et al., 2005).

The color fastness results of the lining leathers differentiated in tanning techniques were found satisfactory for dry rubbing fastness with the value of 5 in terms of felt and leather. The wet felt resulted in $4 / 5$ for all the tanning techniques. However, wet dry rubbing fastness of tanned leathers was determined quite low especially for vegetable and wet-white tanned lining leathers. These results indicated that tanned leathers meet the standards of UNIDO recommended for lining leathers (UNIDO, 1996) except wet leather rubbing results of vegetable and wet-white lining leathers (Table 2).

Table 2. To and fro rubbing fastness results of lining leathers

\begin{tabular}{lcccc}
\hline Tanning techniques & \multicolumn{2}{c}{ Dry } & \multicolumn{2}{c}{ Wet } \\
& Felt & Leather & Felt & Leather \\
\hline Chrome & 5 & 5 & $4 / 5$ & 3 \\
Vegetable & 5 & 5 & $4 / 5$ & 2 \\
Wet-white & 5 & 5 & $4 / 5$ & 1 \\
Semi & 5 & 5 & $4 / 5$ & 3 \\
\hline
\end{tabular}

The crockmeter fastness results of the lining leathers tanned with different tanning materials are given in Table 3. For wet and dry crockmeter fastness results were found quite satisfactory and correlated with the 'to and dry' rubbing fastness results. On contrary to 'to and fro' wet rubbing fastness result of chrome tanned lining leathers, the crockmeter result of chrome tanned lining leather had higher fastness values.

Table 3. Crockmeter fastness results of lining leathers

\begin{tabular}{lcccc}
\hline Tanning techniques & \multicolumn{2}{c}{ Dry } & \multicolumn{2}{c}{ Wet } \\
& Fabric & Leather & Fabric & Leather \\
\hline Chrome & 5 & 1 & $4 / 5$ & 1 \\
Vegetable & 5 & 1 & 4 & 2 \\
Wet-white & $4 / 5$ & 1 & $4 / 5$ & 1 \\
Semi & 5 & 1 & 4 & 2 \\
\hline The evaluation of the leather for crockmeter; 1 good; 2 medium; 3 poor
\end{tabular}

Color fastness to perspiration tests results were presented in Table 4 in terms of wool, acrylic, polyester, nylon, cotton, and acetate. According to the UNIDO quality standards, the felt wouldn't be under 3 according to grey scale for the lining leathers with aniline finishing including the color fastness to perspiration (UNIDO, 1996) which indicates the tanned leathers were significantly fulfilled the requirements of UNIDO.

Color fastness to perspiration values of lining leathers were evaluated both for grain and sued side of the leathers (Table 4). The perspiration results indicated that all lining leathers had quite good values and not fewer than 3 according to grey scale. Only the vegetable lining leather had 3 grey scale values for cotton and acetate. 
ICAMS $2016-6^{\text {th }}$ International Conference on Advanced Materials and Systems

Table 4. Color fastness to perspiration values of lining leathers

\begin{tabular}{lcccccccc}
\hline & \multicolumn{2}{c}{ Chrome } & \multicolumn{2}{c}{ Vegetable } & \multicolumn{2}{c}{ Wet-white } & \multicolumn{2}{c}{ Semi } \\
& Grain & Sued & Grain & Sued & Grain & Sued & Grain & Sued \\
\hline Wool & $4 / 5$ & $4 / 5$ & $3 / 4$ & $3 / 4$ & $4 / 5$ & 5 & $3 / 4$ & 4 \\
Acrylic & $4 / 5$ & 5 & 4 & 4 & $4 / 5$ & $4 / 5$ & $4 / 5$ & $4 / 5$ \\
Polyester & 5 & 5 & 4 & 4 & $4 / 5$ & $4 / 5$ & $4 / 5$ & $4 / 5$ \\
Nylon & 5 & 5 & 4 & $3 / 4$ & $4 / 5$ & $4 / 5$ & $4 / 5$ & $4 / 5$ \\
Cotton & 5 & 5 & 3 & 3 & $4 / 5$ & $4 / 5$ & 4 & 4 \\
Sec. Cell. & 5 & 5 & 3 & 3 & $4 / 5$ & $4 / 5$ & $4 / 5$ & $4 / 5$ \\
Acetate & & & & & & & & \\
\hline
\end{tabular}

Water absorption and perspiration properties of vegetable and semi tanned lining leathers were found higher and comparable respectively than that of chrome and wetwhite tanned leathers although the rubbing fastness values were no better. These characteristics investigated in the study made the all leathers to be used in the producing of lining leathers.

\section{CONCLUSION}

In this study, the effect of four different tanning techniques was investigated on properties of lining leathers produced from goat skins in terms of dynamic and static water absorption, color fastness to perspiration, to and fro and crockmeter rubbing fastness tests. The results of the study showed that all tanning techniques provided high quality lining leathers. But in the ecological point of view, semi and vegetable tanned lining leathers could be selected for the production of lining leathers due to their high water absorption capacity.

\section{Acknowledgement}

The authors would like to thank to Zeta Chemicals, TR for providing pickled goat leathers and Turkey Prime Ministry State Planning Organization for the supply of equipments (Project no: 2007 DPT 001). Also thank to specialist Mete Saglam for his help in leather manufacturing.

\section{REFERENCES}

ASTM D5053. (2003), "Standard test method for color fastness of crocking leather", Annual book of ASTM standards United States, 15(04, 2.

Bitlisli, B.O., Karavana, H.A., Basaran, B. and Aslan, A. (2005), "Importance of Using Genuine Leather in Shoe Production in Terms of Foot Comfort", Journal of the Society of Leather Technologists and Chemists, 89, 107-110.

Diebschlag, W., Muller-Limmroth, W. and Mauderer, V. (1976), "The Influence of Several Socks and Linings on the Microclimate in Shoes with Upper Material of Leather or Synthetic", Journal of the American Leather Chemists Association, 71(6), 293.

Hernon, J.T. (1981), “Alum-Formaldehyde Tannage V. with Zirconium. Domestic U.S. Sheepskins For AllWhite Tanned Reverse Sueded Shoe Linings - Technical Note", Journal of the American Leather Chemists Association, 76(6), 223.

ISO 105-A03 (1993). "Textiles-Tests for color fastness - Part A03: Grey scale for assessing staining", International Organization for Standardization (ISO), Geneva, Switzerland.

Śmiechowski, K., arłok, J., and Kowalska, M. (2014), "The Relationship between Water Vapour Permeability and Softness for Leathers Produced in Poland", Journal of the Society of Leather Technologists and Chemists, 98, 259-236. 


\section{Effect of Various Tanning Processes on Characteristics of Lining Leathers}

Sari, Ö. and Basaran, B. (1996), "Various physical properties of uppers in shoes with lining and their effect on foot comfort", II. National Shoe and Side Industry Symposium Papers, Konya Chamber of Commerce, Konya, Turkey, Publication No. 2, 49-66.

Sari, Ö. and Bitlisli, B.O. (1996), "Sole leather production in Turkey and evaluation of its quality levels", II. National Shoe and Side Industry Symposium Papers, Konya Chamber of Commerce, Konya, Turkey, Publication No. 2, 94-106.

Shuttleworth, S.G. (1973), "Future Developments in Leather Manufacture", Journal of the Society of Leather Technologists and Chemists, 57, 1-4.

TS EN 344-1 (1998), "Safety, protective and occupational footwear for Professional use-part 1: requirements and test methods", Turkish Standardization Institute, Ankara, Turkey.

TS EN ISO 2418 (2006), "Leather - Chemical, physical and mechanical and fastness tests-Sampling location", Turkish Standard Institute, Ankara, Turkey.

TS EN ISO 2419 (2006), "Leather - Physical and mechanical tests - Sample preparation and conditioning", Turkish Standard Institute, Ankara, Turkey

TS 4117 EN ISO 2589 (2006), "Leather - Physical and mechanical tests - Determination of thickness", Turkish Standard Institute, Ankara, Turkey.

TS 4123 EN ISO 2417 (2005), "Leather - Physical and mechanical tests - Determination of the static absorption of water", Turkish Standard Institute, Ankara, Turkey.

TS 8541 EN ISO 5403 (2006), "Leather - Physical and mechanical tests - Determination of water resistance of flexible leathers (ISO 5403:2002)", Turkish Standard Institute, Ankara, Turkey.

TS EN ISO 11641 (2012), "Leather - Tests for color fastness - Color fastness to perspiration", Turkish Standard Institute, Ankara, Turkey.

TS EN ISO 11640 (2013), "Leather-tests for color fastness-Color fastness to cycles of to-and-fro rubbing", Turkish Standard Institute, Ankara, Turkey.

UNIDO (1996), "Acceptable quality standards in the leather and footwear industry", Vienna. 